\title{
APRENDIZAGEM BASEADA EM PROBLEMAS (ABP): UM MÉTODO DE APRENDIZAGEM INOVADOR PARA O ENSINO EDUCATIVO
}

\author{
S. C. SOUZA ${ }^{1 *}$ e L. DOURADO ${ }^{2}$ \\ ${ }^{1}$ Instituto Federal de Educação, Ciência e Tecnologia do Rio Grande de Norte - IFRN \\ ${ }^{2}$ Universidade do Minho (Portugal) \\ samir.souza@ifrn.edu.br
}

Artigo submetido em março/2015 e aceito em setembro/2015

DOI: $10.15628 /$ holos.2015.2880

\section{RESUMO}

A prática de ensino, ainda hoje, não diferente do que ocorreu durante muito tempo, consiste, essencialmente, no modelo de aula em que o professor transmite um conteúdo com breve momento de discussão e atividades as quais o aluno, após memorizar as informações, tem de responder. Algumas estratégias metodológicas de ensino diferenciadas vêm sendo desenvolvidas por professores, que acreditam ser possível promover mudanças em suas práticas pedagógicas, tendo em vista uma aprendizagem significativa. A Aprendizagem Baseada em Problemas (ABP) surge como uma dessas estratégias de método inovadoras em que os estudantes trabalham com o objetivo de solucionar um problema real ou simulado a partir de um contexto. Trata-se, portanto, de um método de aprendizagem centrado no aluno, que deixa o papel de receptor passivo do conhecimento e assume o lugar
\end{abstract}

de protagonista de seu próprio aprendizado por meio da pesquisa. Este artigo constitui-se em uma revisão da literatura básica sobre a Aprendizagem Baseada em Problemas. O objetivo é apresentar a ABP como um método de aprendizagem significativo e eficaz, que pode ser utilizado nos diversos níveis de ensino e nas mais diferentes disciplinas. Por meio de uma investigação do estado da arte sobre a ABP, buscamos refletir acerca da sua importância como método de aprendizagem. A ABP tem apresentado resultados positivos, observados por pesquisadores das mais diferentes áreas, os quais a utilizaram como método de aprendizagem, seja em cursos universitários, seja na educação básica. Espera-se, com este artigo, possibilitar a reflexão sobre novas estratégias de aprendizagem para um ensino educativo.

PALAVRAS-CHAVE: Educação; Ensino; Método de Aprendizagem; Aprendizagem Baseada em Problemas (ABP).

\section{PROBLEM-BASED LEARNING (PBL): A LEARNING METHODOLOGY FOR INNOVATIVE EDUCATIONAL TEACHING}

\begin{abstract}
The teaching practice, still today, no different from what happened for a long time, is essentially the class model where the teacher transmits content with brief moment of discussion and activities which the student, after storing the information, has to answer. Some methodological strategies of differentiated education have been developed by teachers who believe they can make change in their teaching practices, aiming at a meaningful learning. The Problem-Based Learning (PBL) emerges as an innovative method of these strategies in which students work in order to address a real or simulated from a context problem. It is, therefore, a method of learning student-centered, which makes the role of passive recipient of knowledge and takes the place
\end{abstract}

of the protagonist of their own learning through research. This article constitutes a review of basic literature on Problem-Based Learning. The aim is to present the PBL as a method of meaningful and effective learning, which can be used in different educational levels and in many different disciplines. Through a state of the art research on $\mathrm{PBL}$, we seek to reflect on its importance as a learning method. The PBL has shown positive results observed by researchers from different areas, which they used it as a method of learning, whether in university courses either in basic education. Hopefully, with this article, make it possible to reflect on new learning strategies for an educational school.

KEYWORDS: education; teaching; learning method; problem-based learning; PBL. 


\section{INTRODUÇÃO}

Um dos maiores desafios da educação na atualidade é promover reformas que, de fato, acompanhem o desenvolvimento científico, tecnológico, social, cultural, econômico e ambiental, tendo em vista contribuir para o desenvolvimento de uma sociedade mais justa, social e economicamente. O processo de reforma na educação, que, inevitavelmente, traz diversas mudanças, entre as quais romper com estruturas rígidas e com o modelo de ensino tradicional (LIBÂNEO, 1992; FREIRE, 1996, 2011; CAMBI, 1999; MIZUKAMI, 1986; SAVIANI, 1991) precisa investir na formação de professores com vistas ao desenvolvimento de competências que lhes permitam recuperar a dimensão essencial do ensino e da aprendizagem, que é a produção de conhecimento pertinente (MORIN, 2000) e significativo para contribuir com a formação de profissionais que irão atuar na sociedade, de forma inovadora e ética, com o cuidado necessário nas relações entre os seres humanos e o meio ambiente.

Muitas vezes, as experiências inovadoras são introduzidas a partir de práticas de ensino individuais bem sucedidas, cujos docentes alcançaram resultados de destaque em sua atuação pedagógica, facilitando, por isso, sua disseminação e ampliação nas demais instituições. Assim, na contramão do modelo tradicional de ensino, as experiências desenvolvidas buscam inovar, tendo em vista a exploração de novas possibilidades no contexto educacional, para mobilizar processos significativos de mudança.

Nesse cenário, em que se visa à satisfação da demanda por novas formas de trabalhar com o conhecimento, surge a Aprendizagem Baseada em Problemas (ABP) como um método de aprendizagem inovador, contrapondo-se aos modelos didáticos de ensino apoiados em perspectivas ditas tradicionais, em que o professor é o centro do processo de transmissão de saberes para alunos que apenas recebem e memorizam o conhecimento transmitido.

Este artigo constitui-se, metodologicamente, em uma revisão da literatura básica sobre a Aprendizagem Baseada em Problemas. Configura-se como uma investigação do estado da arte sobre a ABP. A revisão da literatura é um método sistemático de coleta de conhecimentos já produzidos, para identificar, avaliar e interpretar de forma crítica o conhecimento em um determinado campo de estudo. A escolha dos referenciais estudados se deu pelo crítério cronológico de produção das obras, levando-se em consideração os autores clásicos do estudo da $A B P$, os principais autores do período intermediário, em que a $A B P$ teve sua expanção em outros países, áreas de conhecimento e autores mais atuais que desenvolveram pesquisas na fase de consolidação do método e avaliação do campo de estudo. Outro critério levado em consideração na escolha dos referenciais partiu da experiência vivenciada com o grupo de investigadores do Instituto de Educação da Universidade do Minho em Portugal, que possui uma larga experiência no desenvolvimento de pesquisa sobre ABP.

A partir dos critérios mencionados, os referenciais foram coletados em bibliotéca física e digital e adquiridos em livrarias. Os artigos foram coletados em portais de periódicos e repositórios de universidades, o que proporcionou a recolha de um número significativo da melhor produção bibliográfica sobre o tema. A análise dos referenciais coletados foi baseada em uma leitura crítica, para além da mera identificação e descrição de estudos já realizados, o que proporcionou a produção de um conhecimento aprofundado do tema para discutir pressupostos, conceitos, processos e resultados, que de forma criativa foram articulados com os diversos estudos, para compreender o significado da relação entre o tema e o contexto do tema. Assim, buscamos refletir 
criticamente acerca da importância da ABP como método de aprendizagem e apresentamos os seus aspectos conceituais e históricos, bem como as características e etapas do processo de aprendizagem; em seguida, apresentamos como ocorre o processo de avaliação na ABP e realizamos uma análise crítica das vantagens e dificuldade da ABP na construção da aprendizagem.

Sob tal perspectiva, o objetivo do artigo é apresentar a Aprendizagem Baseada em Problemas como um método de aprendizagem inovador tendo em vista um ensino educativo e que pode ser aplicado em todos os níveis, da educação básica à Pós-Graduação.

\section{APRENDIZAGEM BASEADA EM PROBLEMAS: ASPECTOS CONCEITUAIS E HISTÓRICOS}

\subsection{Aspectos conceituais}

A Aprendizagem Baseada em Problemas é um método de aprendizagem que, nos últimos anos, tem conquistado espaço em inúmeras instituições educacionais de ensino superior (nos cursos de graduação e pós-graduação) e no ensino básico em diversas disciplinas.

A leitura dos referenciais teóricos sobre ABP apresenta-nos definições variadas acerca da temática. Cada uma delas traz contribuições importantes para a compreensão do seu significado, o que permite um melhor desenvolvimento do processo de aplicação nas mais diversas áreas do conhecimento e níveis de ensino, contribuindo para o avanço desse campo de pesquisa.

Na concepção de Barrows (1986), a ABP representa um método de aprendizagem que tem por base a utilização de problemas como ponto de partida para a aquisição e integração de novos conhecimentos. Em essência, promove uma aprendizagem centrada no aluno, sendo os professores meros facilitadores do processo de produção do conhecimento. Nesse processo, os problemas são um estímulo para a aprendizagem e para o desenvolvimento das habilidades de resolução.

Na definição dada por Delisle (2000, p. 5), a ABP é "uma técnica de ensino que educa apresentando aos alunos uma situação que leva a um problema que tem de ser resolvido". Lambros (2004), em uma definição muito semelhante à de Barrows (1986), afirma que a ABP é um método de ensino que se baseia na utilização de problemas como ponto inicial para adquirir novos conhecimentos. Já Barell (2007) interpreta a ABP como a curiosidade que leva à ação de fazer perguntas diante das dúvidas e incertezas sobre os fenômenos complexos do mundo e da vida cotidiana. Ele esclarece que, nesse processo, os alunos são desafiados a comprometer-se na busca pelo conhecimento, por meio de questionamentos e investigação, para dar respostas aos problemas identificados.

Leite e Esteves (2005) definem a ABP como um caminho que conduz o aluno para a aprendizagem. Nesse caminho, o aluno busca resolver problemas inerentes à sua área de conhecimento, com o foco na aprendizagem, tendo em vista desempenhar um papel ativo no processo de investigação, na análise e síntese do conhecimento investigado.

Em concurso com essas várias definições, apresentamos a ABP como uma estratégia de método para aprendizagem, centrada no aluno e por meio da investigação, tendo em vista à produção de conhecimento individual e grupal, de forma cooperativa, e que utiliza técnicas de 
análise crítica, para a compreensão e resolução de problemas de forma significativa e em interação contínua com o professor tutor.

Podemos constatar que, na extensa literatura produzida sobre $A B P$, existe um consenso acerca de suas características básicas. Numa percepção comum, todos admitem que a ABP promove a aquisição de conhecimentos, o desenvolvimento de habilidades, de competências e atitudes em todo processo de aprendizagem, além de favorecer a aplicação de seus princípios em outros contextos da vida do aluno. Assim, a ABP apresenta-se como um modelo didático que promove uma aprendizagem integrada e contextualizada.

O benefício da interação que a ABP promove é fundamental para alcançar o sucesso na sua aplicação. Isso porque ela é necessária em todos os sentidos: com o tema e com o contexto do tema estudado, entre os alunos e o professor tutor; enfim, entre todos. A estrutura da ABP se constrói sobre essa base, uma vez que a interação é a chave do processo de aprendizagem.

Não obstante, outras dimensões da aprendizagem também são mobilizadas com a ABP, tais como: a motivação, que é estimulada pela curiosidade sobre os temas de cada área de estudo e as habilidades de comunicação individual e grupal, fundamentais para o desenvolvimento da aprendizagem pelo grupo.

A estrutura da ABP foi concebida justamente para que o aluno desenvolva habilidades e capacidades para proceder à investigação de forma metódica e sistemática; para aprender a trabalhar em grupo cooperativo e alcançar os resultados da pesquisa, de forma satisfatória, complementando sua aprendizagem individual.

\subsection{Aspectos históricos}

Ao longo da história da educação, vários modelos didáticos e teorias de ensino e aprendizagem foram criados para contribuir, de forma mais eficaz, no processo educacional. Por volta do final do século XIX e início do século XX, surgiu o movimento progressista na educação, conhecido como Escola Nova, que desenvolveu novas práticas de ensino centradas na aprendizagem e com o foco principal no aluno como protagonista de sua própria aprendizagem. Esse movimento teve como representantes exponenciais os educadores John Dewey (1859-1952), Maria Montessori (1870-1952), Henri Wallon (1879-1962), Célestin Freinet (1881-1966), Lev Vygotsky (1896-1934), Jean Piaget (1897-1980), entre outros que desenvolveram experiências educacionais inovadoras e que se contrapunham ao modelo tradicional de educação vigente (ROCHA, 1988).

Na teoria pedagógica de John Dewey, encontra-se a mais significativa inspiração para a Aprendizagem Baseada na Resolução de problemas. A Pedagogia Ativa ou Pedagogia da Ação, de Dewey, propõe que a aprendizagem deve partir de problemas ou situações que propiciam dúvidas ou descontentamento intelectual, pois os problemas surgem das experiências reais que são problematizadas e estimulam a cognição para mobilizar práticas de investigação e resolução criativa dos problemas (CAMBI, 1999). Delisle (2000) e O'Grady et al. (2012) também apontam Dewey como um dos inspiradores da ABP. Segundo eles, Dewey acreditava que para estimular o pensamento de um aluno, o professor teria de partir de um assunto de natureza não formal, que viesse da vida; do cotidiano dele. 
A partir da iniciativa de um grupo de professores da Universidade de McMaster, no Canadá, no final dos anos de 1960, o modelo da ABP se expandiu para muitas escolas de medicina em todo o mundo. Não restam dúvidas de que a ABP foi influenciada por diversos pensadores que, na busca por transformar o ensino, realizaram experiências pedagógicas inovadoras. Vários autores, como, por exemplo, Delisle (2000); Savin-Baden \& Major (2004); Hillen et al. (2010); Hill \& Smith (2005); O'Grady et al. (2012) são unânimes em confirmar a origem e o desenvolvimento do termo ABP, no modelo atual, a partir da experiência na Universidade de McMaster no Canadá, mais especificamente na faculdade de Medicina, em 1969.

Howard Barrows é apontado como um dos principais articuladores da equipe de professores formada por Jim Anderson e John Evans, que pensaram o currículo da faculdade de medicina, a partir de 1966, implantado oficialmente em 1969 (HILLEN et al., 2010). Com o intuito de promover o desenvolvimento das capacidades dos alunos para contextualizar os conhecimentos teóricos adquiridos na faculdade, pondo-os em prática no cotidiano, de forma competente e humana, Barrows compreendia que, para realizar esse objetivo, os médicos precisavam, além de possuir o conhecimento teórico, saber utilizá-lo na prática (DELISLE, 2000; O'GRADY et al., 2012).

Explica-se, assim, porque o desenvolvimento e a difusão da ABP no Canadá, Estados Unidos e por toda a Europa alcançou excelentes resultados. Um sucesso, aliás, bem justificado, no processo de ensino, pelas características peculiares da ABP: é um método centrado na aprendizagem, que tem por base a investigação para a resolução de problemas contextualizados e que envolve os conhecimentos prévios dos alunos, facilitando o desenvolvimento das competências necessárias ao trabalho profissional; desenvolve a capacidade crítica na análise dos problemas e na construção das soluções; desenvolve a habilidade de saber avaliar as fontes necessárias utilizadas na investigação, bem como estimula o trabalho cooperativo em grupo (DUCH et al., 2001; LEVIN, 2001; O'GRADY et al., 2012). Cabe ressaltar, ainda, que a ABP, ao se espalhar pelo mundo, não ficou restrita apenas à área da saúde; também assimilada por várias áreas do conhecimento (sendo adaptada às suas respectivas especificidades), tais como: as engenharias, a matemática, a física, a biologia, a química e bioquímica, o direito, a psicologia, a geografia, entre outras, bem como aos diversos níveis de ensino: da educação básica ao nível superior e a pósgraduação (DELISLE, 2000; HILL \& SMITH, 2005; LAMBROS, 2002; 2004).

Cumprindo esse percurso, a Aprendizagem Baseada em Problemas terminou por constituirse um método sistematizado, que permitiu aos professores das mais diversas áreas e níveis de ensino estimular a criatividade de seus alunos, desenvolver a capacidade investigativa e o raciocínio para a resolução de problemas, consolidando-se, assim, como um método de aprendizagem considerado eficaz nas mais diversas instituições de ensino e pesquisa em todo o mundo.

\section{CARACTERÍSTICAS E ETAPAS DO PROCESSO DE APRENDIZAGEM NA ABP}

\subsection{O aluno como centro da aprendizagem na ABP}

Ao analisarmos a prática pedagógica tradicional, apoiada nos procedimentos didáticos de aulas expositivas, em que o professor reproduz e transmite um conteúdo apoiado em um manual didático, para alunos que devem ouvir, ler, decorar e repetir, constatamos que esse ainda é o 
modelo mais comum nas instituições de ensino no Brasil e fora do país. Observamos, também, que esse modelo pedagógico reflete práticas didáticas centradas no professor e no ensino, sustentadas por um paradigma que tem sido pouco eficiente para a educação do século XXI por promover uma visão fragmentada e reducionista nas mais diversas áreas do conhecimento científico, tecnológico, social e cultural.

Visando a uma reorientação de rumos, nesse contexto, busca-se estimular os professores a pesquisar metodologias inovadoras que possibilitem o desenvolvimento das competências dos alunos para a problematização como componente fundamental de um método que seja centrado na aprendizagem. O foco na problematização possibilita uma visão transdisciplinar e tem como ponto de partida o levantamento de questões e a busca de soluções para os problemas identificados nos temas curriculares de cada disciplina, nos respectivos níveis de aprendizagem, com a finalidade de produzir conhecimento.

A opção por uma metodologia de aprendizagem centrada no aluno acentua a importância da $A B P$, vez que, por sua aplicabilidade, estaríamos possibilitando o desenvolvimento de atividades educativas que envolvem a participação individual e grupal em discussões críticas e reflexivas. Mesmo porque esse método compreende o ensino e a aprendizagem a partir de uma visão complexa e transdisciplinar que proporciona aos alunos a convivência com a diversidade de opiniões, convertendo as atividades desenvolvidas em sala de aula em situações ricas e significativas para a produção do conhecimento e da aprendizagem para a vida. Além disso, propicia o acesso a maneiras diferenciadas de aprender e, especialmente, de aprender a aprender (DELISLE, 2000).

Em contraponto, os métodos tradicionais de ensino proporcionam o aprendizado de conceitos num contexto teórico. Para muitos estudantes, o principal produto desse ensino é representado pela memorização. A ABP, por iniciar-se com a apresentação de um problema, envolver discussão em grupo, acompanhamento do professor e a investigação cooperativa, contribui significativamente para conferir mais relevância e aplicabilidade aos conceitos aprendidos.

Parece bem fortalecida a afirmação de que as atividades desenvolvidas em sala de aula deverão estar mais conectadas com o contexto de aprendizagem da área em estudo, sendo os currículos ligados às aprendizagens que se interconectam com o cotidiano, dentro e fora da escola. Sob totais condições, os alunos poderão aprender praticando o que será a sua futura profissão, tornando-se profissionais ativos capacitados a resolver, com autonomia e responsabilidade, os problemas que surgirão no seu dia a dia. Essa atitude de enfrentamento, muito provavelmente Ihes favorecerá o desenvolvimento da habilidade para o diálogo e a partilha de ideias em grupo, argumentando, de forma sistemática, para que a resolução do problema seja satisfatória e eficaz (LAMBROS, 2004; DELISLE, 2000).

Como já foi sublinhado, a ABP enfatiza muito mais a compreensão do que a memorização; mas considera que esta última também é importante para a aprendizagem, pois quanto maior for a compreensão de determinado assunto, mais fácil será a memorização e, consequentemente, a aprendizagem. Entretanto, o aprendizado que fica apenas no nível da memorização tem pouco valor para a vida social e profissional. Esse é um dos principais problemas decorrentes de aulas expositivas que enfatizam o conteúdo apenas no contexto em que foi aprendido. Isso não ocorre quando se utiliza a ABP. Como os problemas são apresentados num contexto real, favorecem a transferência dos conhecimentos e habilidades aprendidos em sala de aula para o mundo do 
trabalho (ALBANESE \& MITCHEL, 1993; DELISLE, 2000). Assim, aderir a um currículo no qual a didática está centrada no aluno e na aprendizagem é o diferencial para promover a inovação na educação.

Interessante observar que, se por um lado a ABP tem como objetivo estimular os alunos a buscarem soluções para os problemas apresentados, por outro lado, os alunos acabam motivados a assumir mais responsabilidade pela própria aprendizagem; afinal, "os modelos curriculares da ABP são largamente construtivistas na sua natureza, pois é dada a oportunidade aos alunos de construírem o conhecimento" (CARVALHO, 2009, p. 35). Tanto é que os estudantes passam a selecionar e a utilizar recursos de investigação e técnicas de coleta de informação com variedade e frequência muito maior que aqueles envolvidos em atividades tradicionais de ensino. Por outro lado, como os professores são vistos não como fontes de respostas, mas como facilitadores da solução de problemas, os estudantes tendem a se tornar mais competentes na busca de informações (ALBANESE \& MITCHEL, 1993; BARELL, 2007; BARRETT \& MOORE, 2011).

A solução de problemas geralmente requer interação social. Por essa razão, a ABP incorpora atividades com uma maior cooperação grupal. "Durante esse tempo, os alunos têm a oportunidade de confrontar, comparar e discutir as suas ideias prévias com as perspectivas dos seus colegas" (CARVALHO, 2009, p. 35). Essas atividades requerem interação social dos estudantes, o que contribui para o desenvolvimento de habilidades interpessoais e para o aprimoramento do espírito em equipe, que são fundamentais para o bom desempenho no mundo do trabalho.

Para a maioria dos estudantes, a ABP é muito mais interessante, estimulante e agradável do que os métodos tradicionais de ensino. Para além disso, oferece aos estudantes muito mais possibilidades de desenvolver seus estudos de maneira independente. A satisfação que os estudantes experimentam, consequentemente, tem muito mais a ver com a estratégia em si do que com o carisma do professor ou com a qualidade dos recursos visuais. De fato, o aluno tornase o protagonista da sua aprendizagem, porque se sente motivado, valoriza os conhecimentos trazidos das suas experiências adquiridas ao longo da vida, amplia e desenvolve o seu potencial para novas aprendizagens. Assim, a aprendizagem torna-se autodirigida, auto-orientada, e motivadora (BARRETT \& MOORE, 2011; BARELL, 2007; LAMBROS, 2004). O currículo centrado na $A B P$ muda o foco do ensino para a aprendizagem: do professor para o aluno como centro do processo de ensino e aprendizagem, levando este à compreensão de que aprender não é apenas adquirir informações, mas processar as informações para transformá-las em conhecimentos.

\subsection{O trabalho em grupo}

Nos métodos tradicionais de ensino, o trabalho em grupo é uma atividade habitual, usada pelos professores, nos cursos superiores, para o estudo de determinado conteúdo. Os grupos se organizam de muitas formas e de acordo com as exigências decorrentes dos tipos de atividades. Os objetivos são os mais variados: organizar os alunos para a leitura e análise de textos; responder questões prontas ou desenvolver alguma atividade que exige troca de conhecimento e discussões que promovam a aprendizagem.

Na ABP, o trabalho em grupo destaca-se como uma forma de atividade em que o aluno valoriza a convivência e se dispõe a participar, de forma criativa, do processo de aprendizagem, buscando criar espaços para o trabalho cooperativo, no qual todos são protagonistas, colaborando para uma aprendizagem mútua e integral (BARRETT \& MOORE, 
2011). Durante o trabalho grupal, em que o processo educativo se desenvolve, o aluno apresenta-se como um investigador reflexivo, competente, produtivo, autônomo, dinâmico e participativo.

Nesse processo, o professor tutor é responsável por definir o tamanho dos grupos, de acordo com a quantidade de alunos, de forma que os grupos atinjam um número em torno de 4 a 5 componentes. Esse quantitativo permite que todos possam se envolver com as atividades e participar de forma colaborativa, igualitária, a fim de favorecer o desenvolvimento das habilidades individuais, apesar das diferentes personalidades, para que haja coesão entre os componentes, o que permitirá chegar a consensos nas discussões (WOODS, 2000; LAMBROS 2004; SAVIN-BADEN \& MAJOR 2004). Decerto um trabalho em grupo sempre revelará divergências e até mesmo membros que não conseguirão se integrar, devido às dificuldades em desenvolver suas competências colaborativas (SAVIN-BADEN \& MAJOR, 2004; CARVALHO, 2009); por isso, 0 professor tutor deve estar atento à formação dos grupos para perceber quando algum membro não está conseguindo participar, seja não se mostrando integrado ao grupo, seja não se mostrando interessado pela forma de trabalho. Diante dessa dificuldade, o professor tutor deverá buscar outras estratégias de integração desses alunos, tais como: verificar o motivo real do desinteresse pelo trabalho; mudar o aluno de grupo, entre outras.

O trabalho em grupo promove a aprendizagem colaborativa, que é uma oportunidade de formação pessoal e social. A colaboração oferece o espaço para a reconstrução do conhecimento, que se configura como um conhecimento da situação problemática; a análise e interpretação de dados; a comparação de pontos de vista divergentes; e a explicação de conceitos e ideias. Assim, a criação de um clima colaborativo é também uma fonte de valores entre os alunos que formam o grupo: a capacidade de escutar e observar o que o outro diz; a solidariedade que surge de maneira espontânea e a solidariedade que é construída entre todos; a busca da verdade nas relações e na maneira de atuar de todos e de cada um dos membros; o potencial de corrigir-se mutuamente e a espera do ritmo de aprendizagem comum, considerando o tempo de cada um. Experimentar essas aprendizagens é uma oportunidade de crescimento enriquecedora que somente o trabalho colaborativo facilita. Nesse sentido, a aprendizagem colaborativa em grupo, na educação superior, é um processo de mudança cultural; o professor tutor é o agente dessa mudança quando, no espaço acadêmico, facilita a aprendizagem por meio de métodos como a ABP (BARRETT \& MOORE, 2011).

Essa aprendizagem em grupo, por meio da $A B P$, é mais um processo do que um resultado. É um desafio a ser introduzido como um processo de investigação e análise de problemas reais. Mas, para isso, é necessário um maior interesse e a assunção de um maior compromisso dos professores para construir novas práticas pedagógicas que consolidem, cada vez mais, a $A B P$ na educação superior. E vale ainda acrescentar que o trabalho em grupo, característico da ABP, admite variações não só no tocante ao tamanho dos grupos, da frequência com que os grupos se encontram para as reuniões mas, também, no que concerne à complexidade dos problemas a serem solucionados (BARELL, 2007; DELISLE, 2000).

Portanto, para os alunos, o trabalho em grupo é um conjunto de atividades que favorece a aprendizagem; o desenvolvimento de competências; o desenvolvimento da comunicação intergrupal e individual, possibilitando também o desenvolvimento da socialização na sala de aula. Em si mesmo, o trabalho em grupo já possibilita o desenvolvimento de todos esses aspectos por todos. Mas isso vai depender diretamente do empenho de cada um no desenvolvimento das 
atividades a serem realizadas pelo grupo. $\mathrm{Na} A B P$, o trabalho em grupo possibilita uma aprendizagem interdisciplinar e cooperativa e, também, proporciona aos alunos refletirem acerca dos métodos tradicionais para poder perceber até que ponto a ABP proporciona uma melhor aprendizagem.

\subsection{O professor como tutor}

A educação, por ser um processo dinâmico, exige do professor uma permanente atualização e mudança nas suas práticas docentes, tendo em vista o desenvolvimento de habilidades diferentes das que tradicionalmente são exercidas em seu fazer pedagógico. Uma dessas habilidades é a de tutor, que lhe exige a capacidade de desenvolver, em sala de aula as relações interpessoais com seus alunos (SAVIN-BADEN \& MAJOR, 2004; O'GRADY et al., 2012), pois, quando há mudanças na postura do professor em sala de aula, consequentemente há mudanças nas relações interpessoais com os alunos e até mesmo com seus pares.

Na dimensão do conhecimento, o mínimo a ser exigido de um professor é o domínio do conteúdo de sua disciplina, mantendo constantemente atualizados os conhecimentos científicos para dar resposta às exigências da evolução dos saberes e às demandas da sociedade. Deve, ainda, conhecer a contribuição da sua disciplina ao avanço tecnológico e identificar os valores éticos presentes na sociedade. Na dimensão didático-pedagógica, é importante que o professor conheça os processos psicológicos que afetam a aprendizagem, assim como os métodos e estratégias didáticas, que, de acordo com as características da disciplina, melhor favoreçam a aprendizagem.

A ABP é um método que contempla como um dos pontos fundamentais de sua aplicação a relação entre o professor, o aluno e o conteúdo a ser estudado e aprendido. Nessa relação, o professor posiciona-se como um mediador, um guia que estimula os alunos a descobrir, a interpretar e a aprender. No desempenho desse papel, assume a função de professor tutor, um criador de situações de aprendizagem (O'GRADY et al., 2012). Além disso, contribui para o desenvolvimento de uma série de princípios didáticos que vinculam o ensino e a aprendizagem com situações reais, reforçando a atividade independente, ativa e responsável do aluno na construção de novas aprendizagens que complementem a relação professor, aluno e conhecimento adquirido.

O reconhecimento da importância do professor tutor vem acompanhado por uma tentativa de delimitar o seu perfil, que se define basicamente por assumir a responsabilidade pela criação e apresentação do cenário problemático; colaborar com o processo de aprendizagem; ajudar na aprendizagem dos conhecimentos conceituais da disciplina; acompanhar o processo de investigação e resolução dos problemas; potencializar o desenvolvimento das competências de análise e síntese da informação; ser corresponsável na organização do espaço de encontro e relações no grupo; favorecer a criatividade que proporciona a independência dos alunos ao abordar os processos cognitivos. Todas essas características do professor tutor são apresentadas em relação às etapas fundamentais no processo de aplicação da ABP.

Em síntese, a função do professor tutor na ABP é a de estimular os discentes a tomarem suas próprias decisões, ajudá-los a definir as regras que nortearão o trabalho do grupo, contribuir com eles na pesquisa dos referenciais importantes na aprendizagem do tema em estudo e orientálos na elaboração do trabalho final, bem como apoiar aqueles que encontrarem dificuldades durante o processo. Nesse sentido, o professor tutor acompanha o processo de aprendizagem e o 
desenvolvimento dos alunos, ajuda a promover a integração do grupo, estimula a exploração dos conhecimentos que os alunos possuem, a fim de que a estes sejam acrescidos os conhecimentos que irão adquirir (LAMBROS, 2004; DELISLE, 2000; O'GRADY et al., 2012; CARVALHO 2009). Assim, o professor tutor é visto como o principal motivador da autonomia na produção do conhecimento dos alunos, tanto individual quanto em grupo (SAVIN-BADEN \& MAJOR, 2004; DELISLE, 2000; O'GRADY et al., 2012; CARVALHO, 2009), sendo um dos responsáveis pelo processo de aprendizagem bem-sucedido.

\subsection{Etapas da aprendizagem baseada em problemas}

A ABP possui uma estrutura básica regida por princípios gerais que lhe permitem, de acordo com o nível escolar, o curso universitário e a disciplina, modelar-se a fim de atender a cada uma das especificidades (BARELL, 2007; LAMBROS, 2004).

De acordo com Leite e Afonso (2001) e Leite e Esteves (2005), a estrutura básica da ABP ocorre em quatro etapas: a primeira inicia com a escolha do contexto real da vida dos alunos para a identificação do problema e a preparação e sistematização, pelo professor, dos materiais necessários à investigação. A segunda etapa segue com os alunos recebendo do professor o contexto problemático. Eles iniciam o processo de elaboração das questões-problema acerca do contexto de que eles têm conhecimento prévio e que aprofundarão. Em seguida, passa-se à discussão dessas questões em grupo (acompanhados pelo professor tutor) para, a partir daí, iniciar o planejamento da investigação para a resolução dos problemas. A terceira etapa é o processo de desenvolvimento da investigação por meio dos diversos recursos disponibilizados pelo professor tutor. Os alunos, nesta fase, apropriam-se das informações por meio de leitura e análise crítica, pesquisam na internet, discutem em grupo o material coletado e levantam as hipóteses de solução. $\mathrm{Na}$ última etapa, elaboram a síntese das discussões e reflexões, sistematizam as soluções encontradas para os problemas, preparam a apresentação para a turma e para o tutor e promovem a autoavaliação do processo de aprendizagem que realizaram.

Nessa passagem, procedemos à apresentação de cada etapa, de forma mais detalhada, para compreender a estrutura básica da ABP e as possibilidades de adaptação para os diversos níveis de ensino, de cursos e de disciplinas.

\subsubsection{A elaboração do cenário ou contexto problemático}

A definição do cenário na ABP é uma das etapas mais importantes, pois a escolha de um bom contexto problemático é garantia de que a investigação desenvolvida pelos alunos seguirá com grande possibilidade de alcançar o objetivo pretendido, que é a aprendizagem do tema investigado (CARVALHO, 2009). Por isso, o cenário deve ser escolhido a partir de um contexto real, que faz parte da vida dos alunos, para que haja uma identificação imediata do problema motivando-os a continuar o desenvolvimento da atividade investigativa.

Para a construção de um bom cenário, é importante que seja dado um título que chame a atenção do aluno e que, de imediato, identifique o tema objeto de estudo. Este pode ser apresentado em diversos formatos; por exemplo: pequenos vídeos, diálogos impressos, reportagens jornalísticas, figuras, texto impresso, banda desenhada, entre outros (BARELL, 2007; BARRETT \& MOORE, 2011). 
Logo a seguir, apresentamos algumas características básicas e fundamentais para a definição de um bom cenário, não esquecendo a necessidade de adaptar essas características ao curso, à disciplina e ao nível da turma:

- Atrair o interesse dos alunos: um bom cenário deve ser capaz de atrair e de mobilizar o interesse do aluno para o tema a ser estudado; estimular a pesquisa para aprofundar os conceitos; ser autêntico, proporcionar a ligação do conteúdo programático da disciplina com situações do cotidiano dos alunos (BARELL, 2007; CARVALHO, 2009).

- Haver correspondência entre conteúdos curriculares e aprendizagem: a correspondência entre o cenário e os objetivos da aprendizagem é fundamental para que os alunos identifiquem que há consistência entre os objetivos definidos no programa da disciplina para a aprendizagem e a aprendizagem de fato (BARELL, 2007; CARVALHO, 2009).

- Possuir funcionalidade: o cenário é funcional quando pode ser facilmente apreendido por meio de leitura escrita (com um vocabulário acessível e bem construído); visual (com imagens de boa qualidade e tamanho); auditiva (o som deve ser limpo, sem ruídos permitindo uma boa audição para a compreensão dos alunos). Além disso, deve conter as informações necessárias e relevantes para despertar a curiosidade do aluno e ativar seu conhecimento prévio; não deve conter elementos que distraiam a atenção do tema principal da investigação; deve ser desafiante e trazer os conhecimentos necessários à formulação dos argumentos conceituais que levarão à resolução dos problemas (BARELL, 2007; BARRETT \& MOORE, 2011; CARVALHO, 2009).

- Ter o tamanho ideal: $O$ cenário não deve ser nem muito extenso nem curto demais, a ponte de impossibilitar os alunos de identificarem o contexto problemático; e nem ser complexo demais, que impeça a compreensão dos conceitos, ou simples demais que impossibilite a reflexão e a discussão acerca do que deve ser aprendido. Assim, o cenário deve ter o tamanho e a clareza necessários para apresentar a ideia e estimular os alunos a contextualizar e desenvolver a investigação para a resolução dos problemas (CARVALHO, 2009).

Convém ressaltar que a construção do cenário problemático é de inteira responsabilidade do professor tutor, salvo nos casos em que as adaptações realizadas pelo tutor cumpram o mesmo objetivo, alcançando resultados semelhantes ou melhores, pelo fato de serem os alunos que, ao receber o tema geral do professor tutor, se organizam em grupos para, diante do contexto real no qual estão inseridos, definir o local onde irão desenvolver a investigação do tema dado. Também é importante lembrar que o professor tutor deve estar constantemente planejando e atualizando os cenários para que o processo tenha sempre a inovação como foco final da investigação e das soluções apresentadas pelos alunos para o contexto problemático.

\subsubsection{As questões-problema}

Nesta fase, após receber o cenário contendo os elementos informativos do contexto problemático da vida real, os alunos formam os grupos, com quatro a cinco componentes (de acordo com o número de alunos da turma), e contam com a ajuda do professor tutor, que exerce um papel apenas de orientar os procedimentos. Assim, iniciam o processo em que buscam identificar as informações que faltam para elaborar as questões-problema; organizam o trabalho 
em grupo (quem vai fazer o quê) e, a partir daí, começam as discussões para a elaboração das questões e o desenvolvimento da investigação acerca do contexto que deverão aprofundar. Seguindo o planejamento elaborado, passam à discussão dessas questões em grupo e com o professor tutor, que tem a competência de esclarecer as dúvidas, escolher e definir quais os problemas mais relevantes para a investigação e resolução, bem como decidir com os discentes como deverão apresentar as questões-problema a serem aprofundadas tendo em vista a sua resolução sobre a ordem hierárquica (LEITE \& AFONSO, 2001).

\subsubsection{A resolução dos problemas}

Nesta terceira fase, acontece todo o processo de investigação no qual os alunos farão uso dos recursos planejados e definidos na fase anterior. Ao apropriar-se das informações, iniciam as pesquisas, tanto em grupo quanto individualmente, trazendo os resultados para um amplo debate em grupo, tendo em vista a resolução das questões-problema, apontando soluções em curto, médio e longo prazo (LEITE \& AFONSO, 2001).

$\mathrm{Na}$ organização do trabalho em grupo, os alunos poderão dividir o tempo para cada atividade a ser realizada; podem, por exemplo, determinar o tempo para as questões que eles devem pesquisar para fazer um diagnóstico seguro e decidir os passos seguintes. Eles combinarão quais áreas todos devem investigar e quais podem ser divididas entre eles. Em média, terão uma semana antes de apresentar os primeiros resultados ao professor tutor. A discussão inicial do problema levará os alunos mais criteriosos a identificar um grande número de áreas complementares ao tema estudado para desenvolver uma pesquisa transdisciplinar. A ABP estimula a busca por soluções transdisciplinares, pois, ao trabalhar com problemas complexos, ainda sem solução, no mundo real, os estudantes têm de aprender a relacionar conhecimentos de diferentes áreas, já que os problemas da vida real não apresentam a divisão acadêmica em matérias e disciplinas. Para isso, os alunos recebem ferramentas a fim de lidar com diferentes paradigmas científicos, conhecimentos tácitos e soluções éticas e aceitáveis e usam conhecimentos de diversas disciplinas (BARROWS \& TAMBLYN, 1980; BARELL, 2007; O'GRADY et al., 2012; LEITE \& AFONSO, 2001).

\subsubsection{Apresentação do resultado e autoavaliação}

Para a apresentação do resultado final do trabalho, será necessária a elaboração de uma síntese das reflexões e debates do grupo, que contenha as soluções para os problemas investigados de forma sistemática, bem como a elaboração de apresentação em slides. É importante que o grupo, ao final do trabalho de investigação, realize a autoavalição grupal e individual, e que esta seja feita com a presença do professor tutor, que acompanhará o processo em cada grupo para verificar se todas as questões-problema foram resolvidas ou não, e se a justificativa para aquelas não solucionadas estão em consonância com o fato de não serem estas, de fato, possíveis de solucionar. Na apresentação final, o professor tutor avaliará o processo da aprendizagem verificando se os conhecimentos conceituais, procedimentais e atitudinais alcançados correspondem a resultados concretos de aprendizagem significativa (LEITE \& AFONSO, 2001). 


\section{A AVALIAÇÃO DA APRENDIZAGEM NA ABP}

$O$ uso da ABP como método de aprendizagem requer uma mudança na concepção e realização da avaliação, já que seus objetivos não se limitam à mera aprendizagem de conhecimentos conceituais por parte dos alunos, mas ao desenvolvimento de competências mentais, direcionadas para, no mínimo, três habilidades: de compreensão científica, por meio de casos do mundo real, de estratégias de raciocínio e de resolução de problemas e de estratégias de aprendizagem autorregulada e autodirigida (DELISLE, 2000; CARVALHO, 2009).

Por possuir uma função no currículo e, consequentemente, no processo de aprendizagem autorregulada, a avaliação na ABP deve ser estruturada de tal forma que os estudantes possam pôr em prática a compreensão dos problemas e suas soluções de forma contextualmente significativas. Assim, o professor tutor necessita pensar quais elementos devem ser avaliados e de que forma avaliá-los. Isso faz com que a avaliação na ABP configure-se como o grande desafio para o professor tutor (SAVIN-BADEN \& MAJOR, 2004; CARVALHO, 2009).

Sabe-se que em todo processo de ensino e aprendizagem a avaliação é um elemento fundamental. Na ABP, essa prática deve ser desenvolvida como parte da aprendizagem e não apenas como um mecanismo de atribuição quantitativa de uma nota ao aluno (SAVIN-BADEN \& MAJOR, 2004; CARVALHO, 2009). Afinal, é justamente pela atividade avaliativa que se obtém o feedback do aluno, no que diz respeito a suas dificuldades no processo de aprendizagem, para que haja tempo de ser feita a reorientação, por parte do professor tutor, ao tema ou conteúdo estudado, no intuito de corrigir as incompreensões e possibilitar o retorno ao percurso de aprendizagem desejado (DELISLE, 2000; CARVALHO, 2009). Bem diferente do que ocorre em um sistema de avaliação tradicional em que a aprendizagem é bloqueada; são realizados testes de múltipla escolha (em que prevalece a memorização) e até mesmo questões que requerem respostas lacônicas, simplistas, as quais podem ser pouco relevantes para avaliar o nível de aprendizagem em que os alunos se encontram.

Outro ponto importante é que o professor tutor compreenda que, na ABP, é fundamental que os alunos se mostrem capazes de desenvolver suas competências para pensar de forma crítica e contextualizada; analisar e sintetizar as informações, construir uma argumentação sólida, justificando bem seus resultados e produzindo conhecimento de forma autônoma; interagir de forma colaborativa; demonstrar organização na apresentação dos resultados e saber comunicar, com clareza e confiança, os resultados alcançados, tanto na modalidade escrita quanto na modalidade oral (DELISLE, 2000; CARVALHO, 2009).

No decorrer do curso ou disciplina, o professor tutor deve coordenar as atividades de forma que a avaliação dos estudantes ocorra durante todo o processo, lançando mão dos recursos didáticos disponíveis, com o objetivo de conhecer as impressões dos estudantes e as dificuldades ou facilidades que estes apresentam em sua aprendizagem. Ao final do curso ou disciplina, a análise das avaliações realizadas pelo professor tutor, ao longo do percurso, é fundamental para a tomada de decisões ou medidas corretivas que permitam melhorar a proposta de trabalho para a próxima turma de estudantes e proceder a uma reflexão sobre as relações tutor-estudante, tutorconhecimento, estudantes-estudantes e estudantes-conhecimento.

Também é responsabilidade do professor tutor preparar os instrumentos de avaliação final de acordo com o que pretende avaliar. Esses instrumentos podem ser de diversos tipos: testes de 
conhecimentos conceituais; elaboração de artigo científico; apresentação oral utilizando slides; elaboração de relatório escrito; portfólio; apresentação em pôster; pequenos vídeos, entre outros que, de acordo com a disciplina ou curso, podem ser propostos pelo professor tutor (LAMBROS, 2004; BARELL, 2007; CARVALHO, 2009).

\section{VANTAGENS E DIFICULDADES DA ABP}

A ABP adaptou-se satisfatoriamente a várias áreas do conhecimento nas últimas décadas. Porém, ainda é necessário um maior desenvolvimento de estudos para que possa continuar avançando. Por tratar-se de um método no qual se entrecruzam diversos modelos pedagógicos (aprendizagem colaborativa, aprendizagem significativa, aprendizagem por meio de projetos, aprendizagem autônoma, entre outros), se for corretamente utilizado, pode produzir experiências de aprendizagem positivas, como vem sendo confirmado por numerosos trabalhos publicados nos últimos anos (DELISLE, 2000; LAMBROS, 2004). Entretanto, advertimos que podem surgir algumas dificuldades no uso da $A B P$, sobre as quais é preciso refletir.

Não é novidade o fato de que toda mudança implica vantagens e desvantagens. Nesse contexto, o reconhecimento das vantagens da ABP frente ao ensino tradicional de aula expositiva tem promovido uma maior difusão do método que, atualmente, é usado em diferentes áreas do conhecimento e em diversos cursos de graduação e até na pós-graduação. Vejamos, a seguir, as vantagens e as dificuldades da utilização da ABP, apresentadas por diversos autores (MARGETSON, 1997; BARELL, 2007; DELISLE, 2000; WOODS, 2002; CARVALHO, 2009).

\subsection{As vantagens da ABP}

Uma primeira vantagem a ser destacada é a motivação ativada pelo dinamismo, que mantém o comportamento dos alunos direcionado para a vontade de aprender. A motivação é o elemento fundamental da aprendizagem, pois desperta o interesse e a curiosidade do discente pelos temas estudados para a obtenção de uma aprendizagem de qualidade, o que vai gerar uma maior satisfação. Essa forma de trabalhar estimula os alunos a envolverem-se mais na aprendizagem devido à possibilidade de interagir com a realidade e observar os resultados desse processo. Com isso se promove a ampliação do conhecimento e a motivação diante da aprendizagem. Além de despertar a criatividade, a motivação é reforçada pelo fato de os alunos trabalharem com problemas que irão enfrentar na sua futura profissão, o que caracteriza uma aprendizagem significativa (MARGETSON, 1997; BARELL, 2007; O'GRADY et al., 2012).

A integração do conhecimento é uma segunda vantagem da ABP. Ela possibilita uma maior fixação e transferência do conhecimento. Ao desenvolver o novo conhecimento integrando-o com o conhecimento prévio, ocorre a integração da aprendizagem, o que permite a transferência, a ampliação e a duração do conhecimento produzido. Pode-se afirmar com isso que o conhecimento é integrado e memorizado de uma forma mais eficaz (MARGETSON, 1997; BARELL, 2007; DELISLE, 2000; WOODS, 2002; CARVALHO, 2009).

A terceira vantagem traduz-se no desenvolvimento da habilidade de pensamento crítico. A complexidade e a diversidade dos campos de formação e de atuação necessitam que o aluno desenvolva a habilidade de pensar o conhecimento de forma crítica e realize uma permanente investigação das informações e dos conhecimentos para, depois, analisá-los criticamente e 
elaborar as questões necessárias à resolução dos problemas. O pensamento crítico estimula a imaginação e a criatividade necessárias à aprendizagem dos conhecimentos conceituais de forma transdisciplinar (MARGETSON, 1997; BARELL, 2007; DELISLE, 2000; CARVALHO, 2009).

A interação e as habilidades interpessoais, que dizem respeito à quarta vantagem, são fundamentais no trabalho em grupo, na relação com o professor tutor e na apresentação final dos trabalhos. A interação implica uma relação geral entre todos os envolvidos na sala de aula, pois a ABP proporciona a aprendizagem não só de resultados das atividades acadêmicas de investigação mas, também, busca alcançar aprendizagens mais amplas de caráter educativo interpessoal para desenvolver habilidades afetivas, de convivência e de personalidade dos alunos. A interação converte-se em um processo no qual os indivíduos participantes aprendem a conviver e trabalhar com outros (MARGETSON, 1997; BARELL, 2007; DELISLE, 2000; WOODS, 2002; CARVALHO, 2009).

\subsection{Dificuldades da ABP}

Existe uma insegurança inicial diante da mudança de método de ensino, pois o novo traz inquietações, dúvidas e questionamentos, ao contrário de um método de ensino convencional. A ABP supõe assumir responsabilidades e realizar novas ações.

O tempo é uma das grandes limitações para o uso da ABP. Não é possível realizar a construção do conhecimento de forma rápida como se faz nos métodos tradicionais. Com a ABP, é necessário mais tempo para que seja possível aos alunos alcançarem um nível de aprendizagem satisfatória. A dificuldade apresenta-se, também, porque, ao fazer com que os alunos sejam ativos e autônomos em sua aprendizagem, se reconhece que o tempo da disciplina deve ser ampliado para a obtenção de um bom resultado, pois, caso não haja esse tempo, os alunos podem se sentir inseguros acerca do conhecimento adquirido. Também o professor tutor necessita de mais tempo para preparar os cenários problemáticos e para acompanhar os alunos no desenvolvimento da aprendizagem por meio da ABP (MARGETSON, 1997; BARELL, 2007; DELISLE, 2000; CARVALHO, 2009).

A inadequação do currículo também dificulta a aplicação da ABP. Como se trata de trabalhar com problemas, os conteúdos de aprendizagem podem ser abordados de forma distinta e com maior ou menor profundidade nas várias disciplinas. Assim, se o currículo não está adequado à $A B P$, haverá um desequilíbrio na aprendizagem do aluno, pois alguns professores trabalharão com a ABP e outros não. Nesse sentido, há uma necessidade de fazer uma análise das relações dos conteúdos das diferentes disciplinas no curso, para que não haja desequilíbrio na aprendizagem. Daí a necessidade de pensar um currículo por meio da ABP (MARGETSON, 1997; BARRETT \& MOORE, 2011; WOODS, 2002).

A limitação dos recursos financeiros constitui-se em mais um entrave. Os professores e os alunos necessitam de referenciais bibliográficos atualizados (e em bom número), de salas amplas, equipadas com mesas, cadeiras e internet, que possibilitem o trabalho de investigação dos conteúdos e problemas apresentados; isso significa mais apoio institucional no que concerne à disponibilização de recursos financeiros (MARGETSON, 1997).

A avaliação constitui um dos principais desafios na educação e para as instituições universitárias. Como etapa fundamental do processo educacional, a avaliação traz muitas dificuldades, incertezas e controvérsias. Na ABP, a avaliação é parte do processo de aprendizagem e da produção do conhecimento individual e grupal. É uma tarefa difícil para os alunos que não 
estão acostumados com o tipo de avaliação que inclui autoavaliação e avaliação dos membros do grupo na presença do professor tutor. Isso faz com que os alunos tenham medo de que seus companheiros recebam uma nota negativa. Assim, a avaliação é considerada difícil e uma complicada tarefa para os professores tutores atentos a uma série de aspectos e reclamações que terão de resolver. Além disso, ainda têm de confrontar-se com sua própria avaliação, que é feita pelos alunos, o que faz com que muitos professores não se exponham, resguardando, particularmente, suas fragilidades; afinal sabem que estão sendo avaliados (MARGETSON, 1997; BARELL, 2007; DELISLE, 2000; WOODS, 2002; CARVALHO, 2009).

A falta de habilidades do professor tutor revela-se uma outra dificuldade. Nem todos os professores possuem as habilidades necessárias para determinadas dinâmicas na $A B P$, o que pode gerar um verdadeiro fracasso na utilização do método. Assim, é de grande importância que o professor tutor conheça bem a ABP para dominar todas as suas etapas e esteja bem preparado para definir novas estratégias durante o processo quando surgirem imprevisibilidades no percurso. Ter competência nas técnicas e dinâmicas de grupo para ser um bom facilitador do processo de construção do conhecimento e aprendizagem é essencial na ABP (MARGETSON, 1997; BARELL, 2007; DELISLE, 2000; WOODS, 2002).

\section{CONSIDERAÇÕES FINAIS}

Sabe-se que o ensino e a aprendizagem são práticas demasiadamente dinâmicas e complexas e que um único método de ensino não produz os resultados esperados na aprendizagem para o exercício profissional. O desenvolvimento rápido do conhecimento científico e tecnológico, as modificações e alterações nos sistemas econômicos, sociais, políticos e no meio ambiente exigem dos profissionais, nas mais diferentes áreas, uma visão multidimensional da realidade em que estão inseridos. Nesse sentido, o processo educacional precisa avançar na introdução de métodos inovadores de ensino e aprendizagem que acompanhem a evolução do conhecimento na formação de profissionais que saibam transferir os conhecimentos teóricos para a prática. Assim, a ABP apresenta-se como um método inovador de aprendizagem utilizado em diversas instituições de ensino dos mais diferentes níveis e tem alcançado resultados importantes na aprendizagem e desenvolvimento de habilidades profissionais. Como se trata de um modelo que não é fixo nem fechado, a ABP pode ser adaptada às diversas realidades e necessidades dos cursos e conteúdos de estudo.

Outra questão importante a observar, e já apontada na literatura sobre métodos de ensino inovadores na educação, é a necessidade do apoio institucional em termos de incentivo, suporte pedagógico e infraestrutura. E não podemos deixar de reconhecer que os ganhos que tornam a ABP um método eficaz, quer na educação superior, quer em outros níveis de ensino, traduzem os benefícios decorrentes da sua capacidade de alcançar objetivos educacionais mais amplos que os alcançados pelas metodologias de ensino tradicionais; ou seja: além da produção de conhecimentos, do desenvolvimento de habilidades e atitudes, os alunos poderão ser bemsucedidos em suas carreiras acadêmicas e profissionais.

A ABP também é um método que aprimora o trabalho do docente na medida em que o estimula a acompanhar o processo de investigação desenvolvido pelos alunos e tomar ciência do modo como eles chegam à solução dos problemas que se propõem resolver. Assim, a ABP contribui com o desenvolvimento da formação continuada do docente, pois os professores são impelidos a 
pensar em outras formas de aperfeiçoar sua prática pedagógica diante dos novos desafios da aprendizagem.

Resumindo, a ABP é um método eficaz por apresentar resultados de aprendizagem importantes, observados por vários professores que o utilizam em suas aulas como método de aprendizagem, seja em cursos universitários, seja em curso de nível médio. Os resultados positivos, mencionados por todos eles são reveladores dos reais benefícios desse método: alguns alunos que não se saem bem no ensino tradicional, na $A B P$, apresentam resultados melhores em sua aprendizagem, pois são mais ativos e comprometidos; os alunos dominam o conhecimento e apresentam seus resultados, com mais segurança, visto serem estes frutos de um processo de investigação e reflexão, conduzidos por eles mesmos e não, simplesmente, se limitam a apresentar respostas prontas a questões dadas pelo professor; os alunos exercitam suas habilidades de formulação de questões-problema e análise crítica do cenário para a compreensão e a resolução dos problemas; os alunos desenvolvem a capacidade de inter-relação e cooperação no trabalho em grupo, pois buscam as informações e avaliam a sua importância para a resolução dos problemas e aprendem com autonomia; por fim, desenvolvem a capacidade de autoavaliação e avaliação do desempenho dos integrantes do grupo.

Assim, trabalhar com problemas reais, por meio da ABP, supõe deixar de lado, a ideia de que aprender significa memorizar conceitos transmitidos de manuais didáticos. Consiste, sim, em processar as informações adquiridas por meio da pesquisa, acrescentando novas compreensões significativas, para a ampliação do conhecimento investigado. Supõe, também, abandonar a compreensão linear dos conceitos para compreender o conhecimento como um processo em que estão envolvidas várias dimensões e variáveis que tanto os professores como os alunos devem levar em consideração, tais como: espaço, tempo, acesso a fontes de informação, investigação da informação correta, posta em comum, de maneira organizada e bem argumentada, além de pôr em prática determinadas habilidades sociais e a disponibilidade de adquirir aquelas relacionadas com a comunicação compartilhada, a escuta ativa e a organização grupal.

Vale dizer, por fim, que a ABP tem sido implementada em escolas urbanas e rurais, com estudantes do nível primário e secundário, com estudantes das mais diversas capacidades e das mais diversas idades e em quase todas as disciplinas. Quando o docente está motivado e conhece a fundo suas técnicas, a ABP obtém o melhor resultado com todos os envolvidos no processo de ensino e aprendizagem. A ABP, também, apresenta conteúdos sólidos e estimulantes; compromete os estudantes em um nível emocional; e promove o desenvolvimento das habilidades necessárias para desenvolver-se em um mundo complexo. Além do mais, contribui com a organização curricular e define as estratégias de ensino a serem aplicadas em combinação com outras estratégias, sempre que os objetivos de aprendizagem exijam uma compreensão mais profunda.

Em se contemplando todos os passos desta abordagem, parece-nos haver suficientes razões para acreditar que a ABP é uma estratégia eficaz, que todos os docentes deveriam incluir em seu repertório didático para novas práticas educacionais no século XXI.

\section{REFERÊNCIAS BIBLIOGRÁFICAS}

1. ALBANESE, M. A.; MITCHELL, S. Problem-Based Learning: A review of literature on its outcomes 
and implementation issues. Academic Medicine, 68, p. 52-81, 1993.

2. BARROWS, H. S.; TAMBLYN, R. M. Problem-Based Learning: an approach to medical Education. New York: Springer Publishing Company, 1980.

3. BARROWS, H. S. A Taxonomy of Problem-Based Learning methods. Medical Education, v.20, p. 481-486, 1986.

4. BARRETT, T.; MOORE, S. New Approaches to Problem-Based Learning. Revitalising your practice in higher education. New York: Routledge, 2011.

5. BARELL, J. Problem-Based Learning. An Inquiry Approach. Thousand Oaks: Corwin Press. 2007.

6. CARVALHO, C. J. A. O Ensino e a Aprendizagem das Ciências Naturais através da Aprendizagem Baseada na Resolução de Problemas: um estudo com alunos de 9o ano, centrado no tema Sistema Digestivo. Dissertação de Mestrado, Universidade do Minho, 2009.

7. CAMBI, F. História da Pedagogia. São Paulo: UNESP, 1999.

8. DELISLE, R. Como realizar a Aprendizagem Baseada em Problemas. Porto: ASA, 2000.

9. DUCH, B. Writing problems for deeper understanding. In: B. DUCH, S. GROH; D. ALLEN (Eds.) The Power of Problem-Based Learning. A practical "how to" for teaching undergraduate courses in any discipline. Virginia: Stylus Publishing, LLC, p. 47-55, 2001.

10. FREIRE, P. Pedagogia do oprimido. 50. ed. São Paulo: Paz e Terra, 2011.

11. . Pedagogia da autonomia. Saberes necessários à prática educativa. 27. ed. São Paulo: Paz e Terra, 1996.

12. HILL, A. M.; SMITH, H. A. Problem-based contextualized learning. In: Steve Alsop et al. (Eds.). Analysing exemplary science teaching - theoretical lenses and a spectrum of possibilities for practice. London: Open University Press, p. 136-145, 2005.

13. HILLEN, H.; SCHERPBIER, A.; WIJNEN, W. History of Problem-Based Learning in Medical Education. In Berkel van $\mathrm{H}$. et al. (Eds.). Lessons from Problem-Based Learning. New York: Oxford University Press, p. 5-12, 2010.

14. LEVIN, B. Introduction. In: B. Levin (Ed.). Energizing Teacher Education and Professional Development With Problem-Based Learning. Alexandria: ASCD - Association for Supervision and Curriculum Development, p. 1-7, 2001.

15. LEITE, L.; AFONSO, A. Aprendizagem baseada na resolução de problemas. Características, organização e supervisão. Boletim das Ciências, 48, p. 253-260, 2001.

16. LEITE, L.; ESTEVES, E. Ensino orientado para a Aprendizagem Baseada na Resolução de Problemas na Licenciatura em Ensino da Física e Química. In: Bento Silva e Leandro Almeida (Eds.). Comunicação apresentada no VIII Congresso Galaico-Português de Psicopedagogia. Braga: CIED - Universidade do Minho, p. 1751-1768, 2005.

17. LAMBROS, A. Problem-Based Learning in K-8 Classrooms - A Teacher's Guide to Implementation. Thousand Oaks: Corwin Press, Inc. 2002.

18. _. Problem-Based Learning in Middle and High School Classrooms - A Teacher's Guide to Implementation. Thousand Oaks: Corwin Press, Inc. 2004.

19. LIBÂNEO, J. C. Democratização da escola pública: a pedagogia crítico-social dos conteúdos. São Paulo: Loyola, 1992. 
20. MARGETSON, D. Why is problem-based learning a challenge? In: David Boud \& Grahame Feletti (Eds.). The Challenge of Problem-Based Learning. 2. ed. edition. London: Kogan Page Limited, p. 36-44, 1997.

21. MIZUKAMI, M. G. N. Ensino: as abordagens do processo. São Paulo: EPU, 1986.

22. O'GRADY, G. et al. One-day, One-problem. An approach to Problem-Based Learning. Singapore: Springer, 2012.

23. ROCHA, F. Correntes pedagógicas contemporâneas. 2. ed. Aveiro: Estante, 1988.

24. SAVIANI, D. Escola e democracia. 24. ed. São Paulo: Cortez, 1991.

25. SAVIN-BADEN, M.; MAJOR, C. Foundations of Problem-Based Learning. New York: Open University Press. 2004.

26. WOODS, D. R. Problem-based Learning: How to Gain the Most from PBL. Hamilton: McMaster University, The Bookstore. 2000. 